\title{
The Role of Prior Knowledge in the Development of Strategy Flexibility: The Case of Computational Estimation
}

\section{Citation}

Star, Jon R., Bethany Rittle-Johnson, Kathleen Lynch, and Natasha Perova. 2009. The role of prior knowledge and comparison in the development of strategy flexibility: The case of computational estimation. ZDM - The International Journal on Mathematics Education, 41, no. 5: 569-579.

\section{Published Version}

doi:10.1007/s11858-009-0181-9

\section{Permanent link}

http://nrs.harvard.edu/urn-3:HUL.InstRepos:4889484

\section{Terms of Use}

This article was downloaded from Harvard University's DASH repository, and is made available under the terms and conditions applicable to Other Posted Material, as set forth at http:// nrs.harvard.edu/urn-3:HUL.InstRepos:dash.current.terms-of-use\#LAA

\section{Share Your Story}

The Harvard community has made this article openly available.

Please share how this access benefits you. Submit a story.

Accessibility 


\section{The Role of Prior Knowledge in the Development of Strategy Flexibility: The Case of Computational}

\section{Estimation}

Jon R. Star

Harvard University

Bethany Rittle-Johnson

Vanderbilt University

Kathleen Lynch and Natasha Perova

Harvard University

Paper submitted to the special issue of ZDM - International Journal of Mathematics Education Original submission: October 2008

Revision: February 2009

Correspondence should be addressed to: Jon R. Star, Graduate School of Education, Harvard University, 442 Gutman Library, 6 Appian Way, Cambridge, Massachusetts, 02138, USA. 01-617-496-2511 (voice), 01-617-496-3095 (fax), jon_star@harvard.edu.

Acknowledgements. Thanks to the University School of Nashville and Hale County Schools for participating in this research. Thanks also to Holly Harris for her help in collecting, coding and analyzing the data reported here. This research was supported with funding from U.S. Department of Education grant R305H050179. 
Running head: PRIOR KNOWLEDGE AND FLEXIBILITY

The Role of Prior Knowledge in the Development of Strategy Flexibility: The Case of Computational

\section{Estimation}




\section{Abstract}

The ability to estimate is a fundamental real-world skill; it allows students to check the reasonableness of answers found through other means, and it can help students develop a better understanding of place value, mathematical operations, and general number sense. Flexibility in the use of strategies is particularly critical in computational estimation. The ability to perform complex calculations mentally is cognitively challenging for many students; thus it is important to have a broad repertoire of estimation strategies and to select the most appropriate strategy for a given problem. In this paper, we consider the role of students' prior knowledge of estimation strategies in the effectiveness of interventions designed to promote strategy flexibility across two recent studies. In the first, 65 fifth graders began the study as fluent users of one strategy for computing mental estimates to multi-digit multiplication problems such as $17 \mathrm{x} 41$. In the second, 157 fifth and sixth graders began the study with moderate to low prior knowledge of strategies for computing mental estimates. Results indicated that students' fluency with estimation strategies had an impact on which strategies they adopted. Students who exhibited high fluency at pretest were more likely to increase use of estimation strategies that led to more accurate estimates, while students with less fluency adopted strategies that were easiest to implement. Our results suggest that both the ease and accuracy of strategies as well as students' fluency with strategies are all important factors in the development of strategy flexibility. 


\section{The Role of Prior Knowledge in the Development of Strategy Flexibility: The Case of Computational Estimation}

Estimation is a critically useful skill in everyday life and in mathematics. We often must make quick computations or judgments of numerical magnitude without the aid of calculator or paper and pencil. In addition to being a fundamental, real-world skill, the ability to quickly and accurately perform mental computations and estimations has two additional benefits: 1) It allows students to check the reasonableness of their answers found through other means, and 2) it may help students develop a better understanding of place value, mathematical operations, and general number sense (Beishuizen, van Putten, \& van Mulken, 1997; National Research Council, 2001). These benefits are encapsulated in the "Adding It Up" report from the National Research Council: "The curriculum should provide opportunities for students to develop and use techniques for mental arithmetic and estimation as a means of promoting deeper number sense" (2001, p. 415). Unfortunately, current instructional methods have not been particularly effective at supporting estimation knowledge. It is well documented that a large majority of students have difficulty estimating the answers to problems in their heads (Case \& Sowder, 1990; Hope \& Sherrill, 1987; Reys, Bestgen, Rybolt, \& Wyatt, 1980; Sowder, 1992).

Given the challenges of mentally computing estimates, it is especially important to have a broad repertoire of estimation strategies and to select the most appropriate (often, computationally easiest) strategy for a given problem and goal (Dowker, Flood, Griffiths, Harriss, \& Hook, 1996; LeFevre, Greenham, \& Waheed, 1993; Lemaire, Lecacheur, \& Farioli, 2000). Thus, students who lack strategic flexibility with computational estimation may experience difficulties in this domain. Strategy flexibility is defined here as knowledge of multiple strategies and the ability to select the most appropriate strategy for a given problem and a given problem-solving goal (Blöte, Van der Burg, \& Klein, 2001; Star, 2005; Star \& Seifert, 2006). We use the term "appropriate" to refer to the strategy that is most efficient for a particular problem, individual, and context (Verschaffel, Luwel, Torbeyns, \& Van Dooren, 2007).

First, strategy flexibility involves knowledge of multiple strategies. Flexible estimators know more than one strategy for computing estimates. Knowledge of multiple strategies has clear benefits for learning and performance; for example, learners with knowledge of multiple 
strategies at pretest are more likely to learn from instructional interventions (Alibali, 1999; Siegler, 1995). In general, and across multiple domains (including elementary mathematics), the benefits of multiple strategies are well documented (Alibali, 1999; Carpenter, Franke, Jacobs, Fennema, \& Empson, 1998; Dowker, 1998; LeFevre, Smith-Chant, Hiscock, Daley, \& Morris, 2003; Resnick \& Ford, 1981; Rittle-Johnson \& Star, 2007; Star \& Rittle-Johnson, 2008, in press; Star \& Seifert, 2006).

A second component of strategy flexibility is the use of efficient strategies; flexible estimators use strategies that are more efficient than others under particular circumstances. Knowledge of strategy efficiency is a fundamental feature of problem-solving expertise and is also a fundamental mechanism supporting learning and development (Siegler, 1996). For example, Blöte and colleagues have found that more skilled students know and select mental addition strategies that most closely match the characteristics of numbers in the problem, because such a matching approach allowed students to solve the problem using the fewest number of steps (Blöte, Klein, \& Beishuizen, 2000; Blöte et al., 2001).

Developing strategy flexibility is related to transfer and conceptual knowledge growth. Students who develop flexibility in problem solving are more likely to use or adapt existing strategies when faced with unfamiliar transfer problems and to have a greater understanding of domain concepts (Blöte et al., 2001; Hiebert \& Wearne, 1996; Resnick, 1980; Rittle-Johnson \& Star, 2007). For example, knowledge of multiple strategies for multi-digit arithmetic calculations was related to greater success on transfer problems and greater conceptual knowledge of arithmetic (Carpenter et al., 1998). In addition, strategy flexibility allows solvers to adapt to contextual or situational demands, including the need to accurately or quickly answer a particular problem (Verschaffel et al., 2007).

\section{Flexibility and Strategies for Estimation}

There are numerous strategies that can be used to compute estimates. Of particular interest here are students' knowledge of and use of three strategies for estimating two-digit multiplication problems. Consider the example problem 26 x 42 (the exact product is 1092). One commonly taught strategy is round both, which involves rounding both numbers to the nearest multiple of ten. For this example, round both would produce an estimate of 30 x 40 or 1200 . Another strategy that can be used is round one, which involves rounding only one number to the 
nearest ten. For example, using round one on this problem would lead to either $26 \mathrm{x} 40$ (1040) or 30 x 42 (1260). Finally, a third strategy that we explore here is truncation, which involves covering up or ignoring the ones digits and multiplying the tens digits and subsequently adding two zeros to the resulting product. For this example problem, truncation yields $2 \square \times 4 \square$ or 8 , and then adding two zeros yields an estimate of 800. Note that truncation is a less familiar strategy than the other two, but it is relatively easy and fast and has been advocated for by researchers on computational estimation for these reasons (e.g., Reys, Reys, Nohda, \& Ishida, 1991; Reys, Rybolt, Bestgen, \& Wyatt, 1982; Sowder \& Wheeler, 1989).

Flexibility in estimation includes choosing the most appropriate strategy for computing an estimate for a given problem. Choosing an appropriate strategy in estimation is complicated by the presence of multiple, at times competing goals. On the one hand, it may be desirable to generate an estimate that is close to the exact answer. For the example problem above, of the three strategies discussed, round one (26 x 40) yields the more proximal estimate. Selecting a strategy that produces the most proximal estimate is challenging, in that some strategies provide a false illusion of always leading to more proximal estimates. In particular, a common heuristic for evaluating strategies for proximity is that the less one rounds, the closer the estimate is to the exact value. In the example problem above $(26 \mathrm{x} 42)$, round both $(30 \mathrm{x} 40)$ provides a more proximal estimate than truncation $(20 \times 40)$, since the former involved rounding 26 up 4 to 30 , while the latter involved rounding 26 down 6 to 20. Similarly, round one (26 x 40) produces a more proximal estimate than round both $(30 \mathrm{x} 40)$, because less error has been introduced by rounding. However, for some problems, round both (and thus more rounding) leads to a more proximal estimate than round one; one such example is 29 x 31. This occurs when the error introduced by rounding one number down helps in compensating for the error in the opposite direction introduced by rounding one number up.

In addition to proximity, another goal involved in computing estimates is ease: One may seek to compute an estimate using the strategy that is computational easiest. Ease is particularly important for estimation because one often must estimate mentally. It could be argued that ease of computation is a subjective and individual judgment; however, in our prior work with middleschool students (Star \& Rittle-Johnson, in press), we have been able to make two important generalizations about estimation strategies and computational ease, using reaction time studies and the choice/no-choice paradigm (Siegler \& Lemaire, 1997). First, for problems where both 
multiplicands are greater than or equal to 20 (e.g., 21 x 34 or 47 x 81), our data indicate that truncation is an easier (e.g., faster) strategy to implement than round both. And second, for problems where one multiplicand is near ten (e.g., $8 \times 42$ or $13 \times 78$ ), round one is easier to implement than round both. Thus, round both is not the easiest strategy, but it sometimes leads to the most proximal answer.

The studies described here explore the development of students' flexibility for computing estimates. We were interested in students' learning of round both, round one, and truncation, and when and how students began to use these strategies to optimize for ease and/or for proximity for given problems.

\section{Prior Knowledge and Flexibility}

Our prior work has explored the effectiveness of instructional interventions designed to promote flexibility. We have identified two interventions that reliably lead to gains in flexibility. Both build upon cognitive-science research suggesting that comparing multiple examples is a critical and fundamental pathway to flexible, transferable knowledge (Gentner, Loewenstein, \& Thompson, 2003; Gick \& Holyoak, 1983; Loewenstein \& Gentner, 2001; Namy \& Gentner, 2002; Schwartz \& Bransford, 1998). First, students who were asked to re-solve previously completed problems using a different strategy and then to reflect on the similarities and differences between the strategies made greater gains in flexibility than those who solved two isomorphic problems (Star \& Rittle-Johnson, 2008). And second, students who compared two worked examples presented side-by-side improved their flexibility more than students who studied the same examples on separate pages (Rittle-Johnson \& Star, 2007). Both of these experimental studies investigated students' learning and flexibility for solving equations.

However, in a recent study, it became clear that students' prior knowledge may impact the effectiveness of interventions designed to promote flexibility (Rittle-Johnson, Star, \& Durkin, 2008). In an experimental study with 236 middle-school students learning how to solve equations, we found that students who were not initially familiar with one or more of the target problem-solving strategies did not make the same gains in flexibility as those who began the study with greater familiarity and fluency with the strategies. This study raised an interesting question that is not well explored in the existing psychological or educational literature on flexibility. If an instructional goal is to promote flexibility -- knowledge of multiple strategies 
and how and when to use these strategies appropriately -- then is it more effective to teach novice students multiple strategies from the beginning, or should learners develop initial fluency with one strategy before increasing their repertoire to include multiple strategies?

Our prior work would suggest that learners need initial familiarity with one strategy before they can become flexible in the use of multiple strategies (Rittle-Johnson et al., 2008). Research on analogical reasoning also provides indirect support for this position: learning from comparing unfamiliar examples is often difficult for young children (Gentner, Loewenstein, \& Hung, 2007; Kotovsky \& Gentner, 1996) and for college students who do not receive additional instructional support (Schwartz \& Bransford, 1998). It seems likely that the processing load for novices to learn multiple strategies simultaneously overwhelms their working-memory capacity (Sweller, van Merrienboer, \& Paas, 1998). In addition to this empirical evidence, teachers also express concern about the high cognitive load inherent in introducing students to multiple new strategies at once (Woodward \& Montague, 2002).

\section{Present Studies}

The goal of the present paper was to continue our exploration of the role of prior knowledge in the effectiveness of interventions designed to promote flexibility. In this paper, we focus on how prior knowledge influenced adoption and flexible use of strategies with different features. We report the results of two studies that focused on computational estimation. In Study 1, 65 fifth graders began the study as fluent users of the round both strategy, while in the Study 2, 157 fifth and sixth graders began the study with moderate to low prior knowledge of strategies for computing mental estimates. Students in both studies participated in a one-week intervention, using a pretest-intervention-posttest design. The intervention focused on comparison of worked examples presented side-by-side versus sequential study of the examples (Rittle-Johnson \& Star, 2007); for the intervention, students were randomly paired with another student in their class, and then pairs of students were randomly assigned to condition, with approximately equal numbers of pairs in each condition within each class.

Note that elsewhere we report on the effects of the intervention on improving flexibility (Star \& Rittle-Johnson, in press); here, our interest is in prior knowledge and flexibility. As a result, we report only those details from our method that are relevant to understanding the impact of prior fluency with estimation strategies on students' development of flexibility. 
An additional aspect of the present work that merits discussion is our attempt to disentangle knowledge of strategies from use of strategies. Most prior research on flexibility assesses students' use of strategies, such as students' ability to generate a strategy for mental estimation (Dowker, 1997) and students' ability to implement a strategy for multi-digit sums. However, in the larger literature on strategy choice, children frequently exhibit utilization deficiencies (Miller \& Seier, 1994), where knowledge of strategies appears to be present but the ability to use these strategies lags behind. Similarly, other studies have shown that students' preferences for more efficient strategies generally preceded their use of the more efficient strategies (Blöte et al., 2001). Thus, in examining the role of prior knowledge on flexibility, it seems important not only to measure students' use of strategies but also their knowledge of strategies. In the studies described below, we used an independent measure of flexibility that targeted students' knowledge of multiple strategies and of strategy efficiency, in addition to more standard and direct measures of flexible strategy use.

\section{Method}

\section{Participants}

In Study 1, participants were fifth grade students, while in Study 2, participants were fifth and sixth grade students. Study 1 was conducted in an urban, private school (School A), and Study 2 was conducted in the same school as well as in a small, rural school (School B).

In Study 1, students in four classes of fifth graders $(N=65 ; 33$ girls and 32 boys $)$ participated. Students' mean age was 10.88 (range: 10.06 years to 11.56 years). The fifth grade was comprised of a majority of Caucasian students and $25 \%$ minority students, of whom $18 \%$ were African-American. Approximately $10 \%$ of students at School A receive financial aid. All students were taught by the same mathematics teacher. In previous lessons, the teacher had covered magnitude estimation (estimating whether the product of two numbers is closest to 1,10 , 100,1000 , etc.).

In Study 2, participants were fifth- and sixth-grade students from two schools. In School A, 69 fifth-grade students participated (32 girls and 37 boys). There were four fifth-grade mathematics classes (all taught by the same teacher) at the school. Students' mean age was 10.6 years (range: 10.0 years to 11.4 years); a majority were Caucasian (23\% minority, with $13 \%$ 
African-American). At School B, 45 fifth graders and 46 sixth graders participated. At School B, fifth grade students' mean age was 10.7 years (range: 10.0 years to 11.8 years) while sixth grade students' mean age was 11.8 years (range: 11.0 years to 13.1 years). There were two fifth grade classes (taught by the same teacher) and two sixth grade classes (taught by the same teacher). Most of participating students were Caucasian. Approximately $36 \%$ of students at School B received financial aid. Across schools, teachers had not taught computational estimation in any of the classes, although some students had received limited instruction on computational estimation in previous grades. Three students were dropped from Study 2 because they were absent from school and missed more than one intervention session. Thus the analysis below for Study 2 includes data from a total of 157 students.

\section{Materials}

\section{Intervention}

The interventions in Study 1 and Study 2 were largely the same. Students were presented with a packet of worked examples, showing hypothetical students' estimates and estimation strategies for multiplying two-digit, and occasionally one- and three-digit, integers. The worked examples focused on the three estimation strategies discussed above. Each packet contained 32 worked examples, with questions at the bottom of each page prompting students to reflect on the estimation strategy or strategies demonstrated on that page. In addition, practice problems were integrated into each packet, where students were asked to compute estimates and answer questions about their choice of strategy. Students also received a brief whole-class lesson and a brief homework assignment each day.

\section{Assessment}

The assessments for Study 1 and Study 2 were very similar. Within a study, the same assessment was used as an individual pretest and posttest and was designed to assess procedural knowledge, flexibility, and conceptual knowledge. The procedural knowledge measure assessed knowledge of how to estimate, using both whole-number multiplication problems (six problems, such as $12 \times 24$ and $113 \times 27$; see Table 1) and transfer problems that involved decimal numbers or division (six problems, such as $1.19 \times 2.39$ and $102 \div 9$; see Table 2). In addition, three mental 
estimation problems assessed students' ability to compute an estimate quickly and mentally; problems were presented one at a time to the class for 5 seconds each, and students had to estimate an answer without writing down anything other than their estimate. Flexibility was assessed in two ways. First, flexible use of strategies was assessed by examining students' strategy use on the six whole-number multiplication problems. Second, flexible knowledge of strategies was assessed by items designed to tap students' ability to recognize, implement, and evaluate multiple strategies for computing estimates. Flexibility knowledge items fell into three categories (see Table 2): (a) Knowledge of multiple strategies; two questions asked students to compute estimates in three different ways; (b) Recognize and evaluate ease of use; two questions assessed whether students knew which strategies were computationally easier to implement; and (c) Recognize and evaluate closeness of estimate; four (Study 1) or five (Study 2) questions assessed whether students knew which strategies resulted in an estimate that was most proximal to the exact value. Flexibility questions were virtually identical in the assessments for Study 1 and Study 2, with minor changes for clarity. Finally, conceptual knowledge items assessed students' knowledge of core concepts related to estimation (see Table 2). The items focused on definitions of estimation as well as acceptance of multiple strategies of estimation and multiple values of estimates and were modified from past research (Sowder, 1992; Sowder \& Wheeler, 1989).

\section{Procedure}

In both Studies 1 and 2, the study occurred during one week of students' regular mathematics class. The procedures for the two studies were very similar. On the first day, students completed a 30-minute written pretest and then were provided with a 10-minute introduction lesson by a member of the research team. The goals of the introduction lesson were to introduce students to the idea of estimation as getting an approximate answer and to show students truncation, an estimation strategy that they may not have been familiar with. On Days 2 and 3, students were divided into pairs to work on the intervention packet. During the partner work, the pairs of students were asked to first explain their answers to the explanation prompts verbally to one another and then write down a summary of their answer on the packet. During the partner work, the regular classroom teacher and members of the project team circulated and provided help when requested (e.g., by re-phrasing and breaking down questions, by providing 
general encouragement and by helping students implement steps during problem solving, without providing any guidance on what to do next or why you might use a particular strategy).

At the conclusion of each class, students were given the same brief homework assignment to practice estimating. Homework assignments consisted of 5 to 10 problems for which students were asked to generate estimates, followed by an opened-ended question such as "Which problem was easiest for you to estimate, and why?". Students did not receive feedback on their homework.

In Study 1, students received a wrap-up lesson and completed the posttest on Day 4. In Study 2, students had additional time to complete the intervention packet before receiving the wrap-up lesson on Day 4. Students in Study 2 completed the posttest on Day 5. Students in Study 2 were given additional time to work on the packets because they were expected to need more time given that they were less familiar with the target content. In both studies, two weeks later, children completed the assessment again to measure retention.

\section{Coding}

The coding of the assessments for Study 1 and Study 2 were again very similar. Students' scores on the conceptual knowledge and flexibility assessments were completed by two independent raters, who subsequently met to resolve all disagreements. On the procedural knowledge items, problems were scored for accuracy of the answer; an accurate estimate was defined as one within $30 \%$ of the exact value (Rubenstein, 1985). In addition to scoring accuracy, students' solution strategies were coded into categories based on the strategy of estimation used (truncation, round both, and round one). Some students used a variety of other, idiosyncratic estimation strategies; in rare cases, students calculated the exact value rather than computing an estimate. In all such cases, these strategies were coded as "other". Inter-rater reliability for coding strategies of estimation (based on $20 \%$ of the sample) was $93 \%$ (exact agreement) for Study 1, and 92\% (exact agreement) for Study 2.

\section{Results}

We begin by describing students' prior knowledge of estimation strategies at pretest and then explore the extent that students' prior knowledge impacted the development of strategy flexibility. 


\section{Knowledge and Strategies at Pretest}

\section{Measures of conceptual knowledge, procedural knowledge, and flexibility}

In Study 1, students' scores at pretest were quite high on all measures, indicating substantial knowledge of estimation strategies prior to our intervention. At pretest, students had quite advanced levels of both procedural knowledge of estimation and procedural flexibility, as well as some conceptual knowledge of estimation (see Table 3). In contrast, students in Study 2 began the study with substantially less knowledge of estimation strategies and concepts. For example, as shown in Table 3, Study 2 students on average were able to generate accurate estimates for 4 or 5 of the 15 pretest procedural knowledge items, whereas students in Study 1 on average were able to generate accurate estimates for 12 of these items.

\section{Students' strategies on pretest familiar procedural knowledge items}

Differences in prior knowledge can also be seen in students' estimation strategies at pretest on the whole-number multiplication problems. In Study 1, almost all students began with considerable fluency with the round both strategy; 92\% of participants used round both on at least one problem. Over one-third of Study 1 students were also familiar with round one (see Table 4). In contrast, Study 2 students used round both much less frequently at pretest. Only $49 \%$ used round both on any problem at pretest, and with round one used very rarely.

\section{Flexibility Knowledge at Posttest}

In both Studies 1 and 2, students made gains in their flexibility knowledge and in procedural and conceptual knowledge (see Table 3). The similar gains in flexibility knowledge came about despite the stark differences in prior knowledge of estimation. In Study 1, students' scores on the flexibility measure rose from $73 \%$ to $89 \%$, while in Study 2 the gains were from $46 \%$ to $68 \%$.

However, looking more closely at the three subscales in the flexibility measure, a more complex picture of the differences between Study 1 and Study 2 emerged. First, consider the multiple ways subscale. The items in this subscale assessed students' knowledge of multiple strategies for generating estimates. Study 1 students' score rose from 75\% to 92\%, while Study 2 students' scores improved much more dramatically, from $24 \%$ to $62 \%$. For example, one 
question in this subscale asked students to generate an estimate for $12 \times 36$ in three different ways. At pretest, $77 \%$ of Study 1 students were able to generate an estimate for this problem in at least two ways; at posttest, $98 \%$ were able to do so. On the same problem, only $11 \%$ of Study 2 students were able to generate an estimate in at least two ways at pretest, while $45 \%$ were able to do at posttest. Study 1 students were almost at ceiling at pretest in their knowledge of multiple strategies, while Study 2, who began the study knowing fewer strategies, experienced much more substantial gains.

A somewhat different picture emerged when examining the ease subscale, which assessed students' knowledge of which strategies led to estimates that were the easiest to compute. Students' scores on the ease subscale were comparable at pretest across the two studies, but Study 1 students' scores grew substantially from $62 \%$ to $89 \%$ while Study 2 students' gains were more moderate, from $58 \%$ to $72 \%$. For example, one question on this subscale asked students to evaluate whether round both or round one was easiest to use for computing an estimate for $27 \mathrm{x}$ 39. (Round both, $30 \times 40$, is easier to mentally compute than round one, $27 \times 40$.) Study 1 students' scores on this item grew from $67 \%$ correct to $91 \%$ correct, while Study 2 students' scores grew only from $70 \%$ correct to $73 \%$ correct. The other question on the ease subscale asked students to evaluate whether round both or truncation was easiest to use for computing an estimate for 172 x 234. (Truncation, or $1 \square$ x $2 \square$, is easier than round both, $170 \times 230$.) Study 1 students' scores on this problem grew from 59\% to $86 \%$ correct, and Study 2 students' scores went up comparably, from $45 \%$ to $71 \%$. Students in both studies made comparable gains in their recognition of the relative ease of the truncation strategy, but Study 1 students made greater strides in their ability to identify the relative ease of round one.

Finally, consider students' evaluation of which strategies provided more proximal (i.e., closer) estimates. Students' gains from the two studies were quite similar, from $76 \%$ to $86 \%$ (Study 1) and from 56\% to 69\% (Study 2). Thus, students in both studies made similar strides in their ability to evaluate strategies based on which yields the closer estimate. For example, students were asked to evaluate (without computing the exact value) whether round both or round one gave the closer estimate for 34 x 42 and 9 x 48 (round one is closer for both problems; $92 \%$ and $83 \%$ of Study 1 students answered these two questions correctly at posttest, as compared to $74 \%$ and $65 \%$ of Study 2 students at posttest) and whether round both or truncation gives a closer estimate for 21 x 39 (round both is closer; $86 \%$ correct at posttest in Study 1 and 
$72 \%$ correct in Study 2) and 31 x 73 (round both and truncation give the same estimate; 96\% correct at posttest in Study 1 and 66\% correct in Study 2). While Study 1 students' performance was higher on all of these items in this subscale, gains from pre- to posttest were quite similar for Study 1 and Study 2 students, indicating similar growth in students' ability to think about estimation strategies and proximity.

Our comparison of students' scores on the independent measure of flexibility knowledge suggests the following with respect to the role of prior knowledge in the development of flexibility. First, students with low prior knowledge in Study 2 made the greatest gains in their knowledge of multiple strategies. Study 2 students began with relatively little knowledge of strategies other than round both, and as a result of the study, increased their knowledge of round both as well as truncation and round one. Second, in addition to learning new strategies, Study 2 students also gained an appreciation of the relative ease of truncation over round both for some problems. In contrast, Study 1 students made relatively small gains in their knowledge of new strategies (likely due to a ceiling effect), but showed superior performance on all subscales and greater gains on questions relating to which strategies were easiest for computing estimates for given problems.

\section{Flexibility Use at Posttest}

To further explore the role of prior knowledge in the development of flexibility, we examined students' use of estimation strategies on the whole-number multiplication problems at posttest. Below we consider students' use of multiple strategies, as well as their ability to select the most appropriate strategy for a given problem on the posttest.

\section{Use of multiple strategies}

As shown in Table 4, Study 1 students chose to use round both quite frequently on the posttest. Recall that $92 \%$ of Study 1 students used round both on at least one pretest problem; $100 \%$ of students used this strategy on at least one problem on the posttest. Use of round one on the posttest also increased; $51 \%$ of students used this strategy on at least one posttest problem. Interestingly, use of truncation fell among Study 1 students; while 14\% of students used truncation on at least one problem at pretest, only 5\% did so at posttest. Among Study 2 students, use of round both jumped to $77 \%$ of students at posttest, from $49 \%$ of students at 
pretest. Similarly, use of round one increased to $17 \%$ of students, and use of truncation increased to $23 \%$ of students.

In addition, Study 1 students were more likely to use multiple strategies on the posttest. $53 \%$ of participants used at least two of the three target strategies (truncation, round one, round two ) on at least one problem on the posttest, as compared to only $29 \%$ of Study 2 students.

\section{Choice of appropriate strategies}

In addition to use of multiple strategies, we also considered whether students switched to a more appropriate strategy on a given problem. Of interest were two potential switches that students could have made.

First, students could have switched from round both to round one on problems where round one was more appropriate. On problems 1 and 2 (see Table 1), round one is easier to implement than round both (Star \& Rittle-Johnson, in press). In addition, for problems 1 and 2 in Study 2, round one yields a closer estimate than round both. To what extent did students in Studies 1 and 2 who used round both on problems 1 and 2 at pretest switch to round one at posttest? For this analysis, we only considered those students who showed some fluency with round both at pretest -- those who used this strategy on at least one pretest item (92\% of Study 1 students and $49 \%$ of Study 2 students). Within this subset of participants, $25 \%$ of Study 1 students switched from round both to round one on problem 1 and/or 2, as compared to only $5 \%$ of Study 2 students (see Table 4).

Second, we also investigated whether students switched from round both to truncation on problems where truncation was appropriate. In our prior work, we have shown that truncation is easier to implement than round both (Star \& Rittle-Johnson, in press). We coded whether students switched from round both (at pretest) to truncation (at posttest) on problems 3, 4, 5, and/or 6. As above, we only considered students who showed some fluency with round both at pretest. Results indicated that only 3\% of Study 1 students switched from round both to truncation on one or more of problems 3-6, while 19\% of Study 2 students made this switch. Note that our interpretation of students' decision to switch or not to switch to truncation is complicated by the fact that, while truncation is easier to implement in problems 3-6, round both produces the most proximal estimate on problems 4, 5, and 6 (and the same estimate as truncation on problem 3). Study 1 students' reluctance to switch to truncation can be seen either 
as a reflection of these students' prioritization of proximity goals or their strong preference for round both in spite of the greater ease of truncation.

\section{Discussion}

The goal of the present paper was to explore the role of students' prior knowledge of estimation strategies in the development of strategy flexibility. We report the results of two very similar studies, conducted with students with quite different prior knowledge profiles. Study 1 students began with significant fluency with the round both strategy, while Study 2 students had substantially less fluency with round both or with any estimation strategy (Study 1 participants had received recent classroom instruction on computational estimation and Study 2 participants had not). Would Study 1 students' fluency with round both aid or hinder their development of strategy flexibility, both in terms of knowledge of multiple strategies and the ability to choose the most efficient strategy for a given problem and problem-solving goal? Our results indicated that prior knowledge did impact the development of flexibility, but in rather complex ways that these studies did not fully explicate, as we elaborate below.

First, there is some evidence that prior knowledge can be a boon to the development of strategy flexibility. Students from both studies made comparable gains on the independent measure of flexibility, but students with greater prior knowledge (in Study 1) made greater improvements in their ability to identify the relative ease of round one. Although Study 1 students relied heavily on round both at pretest, they also showed greater familiarity with round one than did Study 2 students, which likely supported their ability to learn the relative merits of round both and round one in terms of ease. These results are consistent with our prior work suggesting that learners may need initial familiarity with one strategy before they can become flexible with multiple strategies (Rittle-Johnson et al., 2008). In addition to these gains in terms of flexibility knowledge, students with greater prior knowledge also were superior in flexibility use. Study 1 students used a greater diversity of strategies on posttest estimation problems, and they were more likely to switch from round both to round one on posttest problems 1 and 2 -problems where round one is the most appropriate strategy.

However, in other ways, the impact of significant prior knowledge was not as widespread as we might have hypothesized. Students with lower prior knowledge (in Study 2) made greater gains in their knowledge of multiple strategies and made comparable gains in learning the 
relative merits of the truncation strategy in terms of ease and closeness. In addition, Study 2 students were more likely to switch strategies from round both to truncation, which we interpret as a choice to optimize strategies based on ease of computation.

One possible explanation of these findings is that Study 1 and Study 2 students were switching strategies for different reasons. Study 1 students, who began the study able to fluently execute round both, may have switched to round one because of the perception that round one yields a more proximal estimate. Study 1 students would not have been driven to switch strategies by the promise of an easier-to-compute estimation strategy, given their ability to quickly and easily use round both. In contrast, Study 2 students, who typically lacked fluency with round both (or any estimation strategy), may have been more attracted by the truncation strategy because it is very easy and fast to execute. Proximity was perhaps a secondary concern to these Study 2 students, who were likely more interested in learning and using strategies that they could implement easily. Thus round one, which is useful in that it gives a more proximal estimate on problems such as 1 and 2, might be less attractive. In addition, although round one can be easier to implement than round both (Star \& Rittle-Johnson, in press), it is only easier to implement on problems with multiplicands near 10. This more subtle choice to use round one on problems with multiplicands near 10 might have been too difficult for students with low prior knowledge.

These findings have important implications for the assessment of flexibility and for interventions designed to promote flexibility. First, our results underscore the value of including measures of both knowledge and use in assessing flexibility. Our prior work indicates that knowledge develops prior to use (Star \& Rittle-Johnson, 2008), suggesting the importance of knowledge measures to tap emerging flexibility. Similarly, in the present study, our investigation of students' strategy use showed that Study 1 students (who began with greater prior knowledge of estimation strategies) used a limited repertoire of strategies for solving posttest problems, yet our independent flexibility measures indicated that these students did develop sophisticated knowledge about the relative ease and closeness of various estimation strategies that was not reflected in their strategy choices.

Second, when considering the role of prior knowledge in the development of strategy flexibility, there are intuitive explanations for how prior knowledge can help or can hinder learning. On the one hand, students with high prior knowledge may be reluctant to adopt new 
strategies, given their fluency with (and likely preference for) a small set of known strategies. On the other hand, students with minimal prior knowledge may be overloaded by attempts to teach multiple strategies (and the pros and cons of each) at the onset of learning. Our results do not fall into one or the other side of this issue. Rather, an important take-away is that students' prior knowledge plays an important role in the development of strategy flexibility but in ways that are subtle and not completely understood. In particular, prior knowledge did not make students more or less willing to learn about or to adopt new strategies, but rather prior knowledge served as a filter through which students attend to or failed to attend to strategic information about problem solving methods. Study 1 students, who already possessed an easy-to-implement strategy for computing estimates, seemed driven to switch because of the proximity appeal of round one, while Study 2 students, who did not have an easily executable strategy at pretest, were attracted to the ease of execution offered by truncation.

In conclusion, our results indicate that prior knowledge plays an important but complex and nuanced role in the development of strategy flexibility. Flexibility can and should be an instructional goal for all students, but efforts to promote this outcome must carefully consider students' prior knowledge and the ways that such knowledge might promote or hinder students' knowledge of multiple strategies and their ability to select the most appropriate strategy for a given problem. 
Prior knowledge and flexibility 20

\section{References}

Alibali, M. W. (1999). How children change their minds: Strategy change can be gradual or abrupt. Developmental Psychology, 35(1), 127-145.

Beishuizen, M., van Putten, C. M., \& van Mulken, F. (1997). Mental arithmetic and strategy use with indirect number problems up to one hundred. Learning and Instruction, 7(1), 87-106.

Blöte, A. W., Klein, A. S., \& Beishuizen, M. (2000). Mental computation and conceptual understanding. Learning and Instruction, 10, 221-247.

Blöte, A. W., Van der Burg, E., \& Klein, A. S. (2001). Students' flexibility in solving two-digit addition and subtraction problems: Instruction effects. Journal of Educational Psychology, 93, 627-638.

Carpenter, T. P., Franke, M. L., Jacobs, V. R., Fennema, E., \& Empson, S. B. (1998). A longitudinal study of invention and understanding in children's multidigit addition and subtraction. Journal for Research in Mathematics Education, 29(1), 3-20.

Case, R., \& Sowder, J. T. (1990). The development of computational estimation: A neo-Piagetian analysis. Cognition and Instruction, 7, 79-104.

Dowker, A. (1997). Young children's addition estimates. Mathematical Cognition, 3, 141-154.

Dowker, A. (1998). Individual differences in arithmetic development. In C. Donlan (Ed.), The Development of Mathematics Skills (pp. 275-302). London: Taylor and Francis.

Dowker, A., Flood, A., Griffiths, H., Harriss, L., \& Hook, L. (1996). Estimation strategies of four groups. Mathematical Cognition, 2(2), 113-135.

Gentner, D., Loewenstein, J., \& Hung, B. (2007). Comparison facilitates children's learning of names for parts. Journal of Cognition and Development, 8(3), 285-307.

Gentner, D., Loewenstein, J., \& Thompson, L. (2003). Learning and transfer: A general role for analogical encoding. Journal of Educational Psychology, 95(2), 393-405.

Gick, M. L., \& Holyoak, K. J. (1983). Schema induction and analogical transfer. Cognitive Psychology, 15(1), 1-38.

Hiebert, J., \& Wearne, D. (1996). Instruction, understanding, and skill in multidigit addition and subtraction. Cognition and Instruction, 14(3), 251-283.

Hope, J. A., \& Sherrill, J. M. (1987). Characteristics of unskilled and skilled mental calculators. Journal for Research in Mathematics Education, 18(2), 98-111.

Kotovsky, L., \& Gentner, D. (1996). Comparison and categorization in the development of relational similarity. Child Development, 67(6), 2797-2822.

LeFevre, J. A., Greenham, S. L., \& Waheed, N. (1993). The development of procedural and conceptual knowledge in computational estimation. Cognition and Instruction, 11, 95-132.

LeFevre, J. A., Smith-Chant, B., Hiscock, K., Daley, K. E., \& Morris, J. (2003). Young adults' strategies in simple arithmetic: implications for the development of mathematical representation. In A. J. Baroody \& A. Dowker (Eds.), The Development of Arithmetic Concepts and Skills (pp. 203-228). Mahwah, NJ: Lawrence Erlbaum.

Lemaire, P., Lecacheur, M., \& Farioli, F. (2000). Chiildren's strategy use in computational estimation. Canadian Journal of Experimental Psychology, 54(2), 141-148.

Loewenstein, J., \& Gentner, D. (2001). Spatial mapping in preschoolers: Close comparisons facilitate far mappings. Journal of Cognition and Development, 2(2), 189-219.

Miller, P. H., \& Seier, W. L. (1994). Strategy utilization deficiencies in children: When, where, and why. In H. W. Reese (Ed.), Advances in child development and behavior (Vol. 25, pp. 107-156). New York, NY: Academic Press.

Namy, L. L., \& Gentner, D. (2002). Making a silk purse out of two sows' ears: Young children's use of comparison in category learning. Journal of Experimental Psychology: General, 131(1), 5-15.

National Research Council. (2001). Adding it up: Helping children learn mathematics. Washington, DC: National Academy Press.

Resnick, L. B. (1980). The role of invention in the development of mathematical competence. In R. H. Kluwe \& H. Spada (Eds.), Developmental models of thinking (pp. 213-244). New York: Academic Press.

Resnick, L. B., \& Ford, W. W. (1981). The psychology of mathematics for instruction. Hillsdale, NJ: Lawrence Erlbaum. 
Reys, R. W., Bestgen, B., Rybolt, J. F., \& Wyatt, J. W. (1980). Identification and characterization of computational estimation processes used by in-school pupils and out-of-school adults (No. ED 197963). Washington, DC: National Institute of Educationo. Document Number)

Reys, R. W., Reys, B. J., Nohda, N., \& Ishida, J. (1991). Computational estimation performance and strategies used by fifth- and eighth-grade Japanese students. Journal for Research in Mathematics Education, 22(1), 39-58.

Reys, R. W., Rybolt, J. F., Bestgen, B. J., \& Wyatt, J. W. (1982). Processes used by good computational estimators. Journal for Research in Mathematics Education, 13(3), 183-201.

Rittle-Johnson, B., \& Star, J. R. (2007). Does comparing solution methods facilitate conceptual and procedural knowledge? An experimental study on learning to solve equations. Journal of Educational Psychology, 99(3), 561-574.

Rittle-Johnson, B., Star, J. R., \& Durkin, K. (2008). The importance of familiarity when comparing examples: Influences on conceptual and procedural knowledge of equation solving. Manuscript under review.

Rubenstein, R. N. (1985). Computational estimation and related mathematical skills. Journal for Research in Mathematics Education, 16, 106-119.

Schwartz, D. L., \& Bransford, J. D. (1998). A time for telling. Cognition and Instruction, 16(4), 475-522.

Siegler, R. S. (1995). How does change occur: A microgenetic study of number conservation. Cognitive Psychology, 28(3), 225-273.

Siegler, R. S. (1996). Emerging minds: The process of change in children's thinking. New York: Oxford University Press.

Siegler, R. S., \& Lemaire, P. (1997). Older and younger adults' strategy choices in multiplication: Testing predictions of ASCM using the choice/no-choice method. Journal of Experimental Psychology: General, 126(1), 71-92.

Sowder, J. T. (1992). Estimation and related topics. In D. Grouws (Ed.), Handbook of research on mathematics teaching and learning (pp. 371-389). New York: Macmillan.

Sowder, J. T., \& Wheeler, M. M. (1989). The development of concepts and strategies used in computational estimation. Journal for Research in Mathematics Education, 20, 130-146.

Star, J. R. (2005). Reconceptualizing procedural knowledge. Journal for Research in Mathematics Education, 36(5), 404-411.

Star, J. R., \& Rittle-Johnson, B. (2008). Flexibility in problem solving: The case of equation solving. Learning and Instruction, 18, 565-579.

Star, J. R., \& Rittle-Johnson, B. (in press). It pays to compare: An experimental study on computational estimation. Journal of Experimental Child Psychology.

Star, J. R., \& Seifert, C. (2006). The development of flexibility in equation solving. Contemporary Educational Psychology, 31(280-300).

Sweller, J., van Merrienboer, J. J. G., \& Paas, F. G. W. C. (1998). Cognitive architecture and instructional design. Educational Psychology Review, 10(3), 251-296.

Verschaffel, L., Luwel, K., Torbeyns, J., \& Van Dooren, W. (2007). Developing adaptive expertise: A feasible and valuable goal for (elementary) mathematics education? Ciencias Psicologicas, 2007(1), 27-35.

Woodward, J., \& Montague, M. (2002). Meeting the challenge of mathematics reform for students with LD. The Journal of Special Education, 36(2), 89-101. 
Prior knowledge and flexibility 22

Table 1

Whole-Number Multiplication Procedural Knowledge Items, Studies 1 and 2

\begin{tabular}{ccc}
$\#$ & Study 1 problem & Study 2 problem \\
\hline 1 & $12 \times 29$ & $12 \times 24$ \\
2 & $8 \times 72$ & $8 \times 76$ \\
3 & $23 \times 52$ & $23 \times 52$ \\
4 & $37 \times 17$ & $37 \times 17$ \\
5 & $42 \times 28$ & $42 \times 28$ \\
6 & $113 \times 27$ & $113 \times 27$
\end{tabular}


Table 2

Sample Items for Assessing Procedural Knowledge, Flexibility, and Conceptual Knowledge

\begin{tabular}{|c|c|}
\hline Problem Type & Sample Items \\
\hline \multicolumn{2}{|c|}{ I. Procedural Knowledge $\left(\alpha_{\text {Study } 1}=.64 ; \alpha_{\text {Study2 }}=.88\right)$} \\
\hline a. Mental $(N=3)$ & $12 \times 34 ; 23 \times 49$ \\
\hline b. Familiar $(N=6)$ & $12 \times 24 ; 113 \times 27$ \\
\hline c. Transfer $(N=6)$ & $1.19 \times 2.39 ; 102 \div 9$ \\
\hline \multicolumn{2}{|c|}{ II. Flexibility $\left(\alpha_{\text {Study } 1}=.58 ; \alpha_{\text {Study2 }}=.80\right)$} \\
\hline $\begin{array}{l}\text { a. Recognize and evaluate } \\
\text { ease of use }(N=2)\end{array}$ & $\begin{array}{c}\text { Luther computes an estimate for } 27 \text { x } 39 \text { by rounding both numbers and } \\
\text { multiplying } 30 \text { x } 40 \text {. Riley arrives at an estimate by rounding one } \\
\text { number, multiplying } 27 \text { x } 40 \text {. Which way to estimate is easier? }\end{array}$ \\
\hline $\begin{array}{l}\text { b. Knowledge of multiple } \\
\text { strategies }(N=2)\end{array}$ & Estimate 12 x 36 in 3 different ways \\
\hline $\begin{array}{l}\text { c. Recognize and evaluate } \\
\text { closeness of estimate } \\
(N=4[\text { Study } 1] \text { or } 5 \text { [Study } \\
\text { 2]) }\end{array}$ & $\begin{array}{l}\text { Carmine computes an estimate for } 9 \times 48 \text { by rounding both numbers and } \\
\text { multiplying } 10 \times 50 \text {. Radika arrives at an estimate by rounding one } \\
\text { number, multiplying } 10 \times 48 \text {. Without calculating the exact value, which } \\
\text { estimate is closer to the exact value? }\end{array}$ \\
\hline \multicolumn{2}{|c|}{ III. Conceptual Knowledge $\left(\alpha_{\text {Study } 1}=.53 ; \alpha_{\text {Study } 2}=.62\right)$} \\
\hline \multirow[t]{3}{*}{$(N=10)$} & $\begin{array}{l}\text { Rate each definition of estimation as not so good, kind of good, or very } \\
\text { good: "Estimation is making math problems easy and quick," [kind of } \\
\text { good] "Estimation is guessing," [not so good] "Estimation is using easier } \\
\text { numbers and getting close to the true value." [very good] }\end{array}$ \\
\hline & $\begin{array}{l}\text { Kim and Ahmad were asked to estimate } 81 \times 15 . \text { Kim estimated } 80 \text { x } 10 \\
=800 \text {; Ahmad estimated } 80 \text { x } 20=1600 . \text { Is Kim's answer }(800) \text { an OK } \\
\text { estimate? Is Ahmad's answer (1600) an OK estimate? }\end{array}$ \\
\hline & $\begin{array}{l}\text { Will rounding one number always give you a closer estimate than } \\
\text { rounding both numbers? Explain your answer. }\end{array}$ \\
\hline
\end{tabular}

Note: Cronbach's alpha is reported for posttest in both studies. 
Table 3

Proportion Correct on Each Outcome Measure in Studies 1 and 2

\begin{tabular}{|c|c|c|c|c|c|c|c|c|c|c|c|c|}
\hline \multirow[t]{4}{*}{ Knowledge Type } & \multicolumn{6}{|c|}{ Study 1} & \multicolumn{6}{|c|}{ Study 2} \\
\hline & \multirow{2}{*}{\multicolumn{2}{|c|}{ Pretest }} & \multirow{2}{*}{\multicolumn{2}{|c|}{ Posttest }} & \multirow{2}{*}{\multicolumn{2}{|c|}{ Pre/Post Gain }} & \multirow{2}{*}{\multicolumn{2}{|c|}{ Pretest }} & & & \multicolumn{2}{|c|}{ Pre/Post Gain } \\
\hline & & & & & & & & & Posttest & & & \\
\hline & $M$ & $S D$ & $M$ & $S D$ & $M$ & $S D$ & $M$ & $S D$ & $M$ & $S D$ & $M$ & $S D$ \\
\hline Procedural & .77 & .23 & .85 & .14 & .08 & .18 & $.30 * *$ & .31 & $.68 * *$ & .24 & $.37 * *$ & .23 \\
\hline Flexibility & .73 & .22 & .90 & .12 & .16 & .22 & $.46^{* *}$ & .26 & $.68 * *$ & .25 & .21 & .22 \\
\hline Multiple ways & .75 & .30 & .92 & .14 & .18 & .30 & $.24 * *$ & .29 & $.62 * *$ & .27 & $.38 * *$ & .31 \\
\hline Closeness & .77 & .22 & .87 & .18 & .10 & .25 & $.56 * *$ & .32 & $.69 * *$ & .30 & .12 & .29 \\
\hline Ease & .62 & .44 & .88 & .25 & .27 & .48 & .58 & .40 & $.72 * *$ & .40 & $.14^{\tau}$ & .47 \\
\hline Conceptual & .48 & .14 & .57 & .15 & .08 & .13 & $.35 * *$ & .15 & $.47 * *$ & .17 & $.12^{\tau}$ & .16 \\
\hline
\end{tabular}

Note: Scores for Study 1 and Study 2 participants compared using independent sample t-tests, not assuming equal variance. Note that the assessments were very similar, but not identical, so statistical comparisons must be interpreted with some caution.

$* * p<.001,{ }^{\tau} \mathrm{p}<.10$ 
Table 4

Strategy Use on Whole-Number Multiplication Procedural Knowledge Items (Percentage of Participants), by Study

Pretest strategy use ${ }^{\mathrm{a}}$

Used round both on at least one problem

Study $1 \quad$ Study 2

Used round one on at least one problem

92

49

Used truncation on at least one problem

38

Posttest strategy use ${ }^{b}$

Used round both on at least one problem

Used round one on at least one problem

Used truncation on at least one problem

Switching to more efficient strategies ${ }^{\mathrm{c}, \mathrm{a}}$

Switched from round both to round one on problem 1 and/or 2

Switched from round both to truncation on problems 3, 4, 5, and/or 6

${ }^{\text {a }}$ The difference between Study 1 and Study 2 in students' usage of strategies at pretest was marginally significant, $\chi^{2}(2, N=208)=5.94, p=.051$.

${ }^{\mathrm{b}}$ The difference between Study 1 and Study 2 in students' usage of strategies at posttest was significant, $\chi^{2}(2, N=285)=23.2, p<.001$.

${ }^{\mathrm{c}}$ Students in Study 1 and Study exhibited significantly different profiles of strategy switching, $\chi^{2}$ (2, $N=$ 56) $=23.0, p<.001$.

${ }^{\mathrm{d}}$ Of those students who used round both on at least one pretest problem 
Prior knowledge and flexibility 26

\section{Figure Captions}

Figure 1. Sample packet page for A) the compare condition and B) the sequential condition. 
Figure 1

\section{A. Compare condition}

About how much is $27 \cdot 43$ ?

\begin{tabular}{|l|l|}
\hline \multicolumn{1}{|c|}{ Allie's way: } & \multicolumn{1}{c|}{ Claire's way: } \\
$27 * 43$ & My estimate is 1200. \\
My estimate is 800. & I rounded both numbers. \\
$\begin{array}{l}\text { I covered up the ones digits and then } \\
\text { multiplied the tens digit like this: }\end{array}$ & $\begin{array}{l}\text { I rounded } 27 \text { up to } 30 . \\
\text { I rounded } 43 \text { down to } 40 .\end{array}$ \\
$\begin{array}{l}\text { Then } 1 \text { added two zeros because } 1 \text { covered } \\
\text { up two digits and got } 800 .\end{array}$ & Then I multiplied $30 * 40$ and got 1200. \\
\hline
\end{tabular}

3. How is Allie's way similar to Claire's way?

4a, Use Allie's way to estimate $21 * 43$.

4b. Would Claire's way give a different estimate for $21 * 43$ than Allie's way? 


\section{B. Sequential condition}

About how much is $57 * 23$ ?

\section{Claire's way:}

$57 \cdot 23$

My estimate is 1200 .

I rounded both numbers.

I rounded 57 up to 60.

I rounded 23 down to 20 .

Then 1 multiplied $60 * 20$ and got 1200 .

2a. Is this an OK estimate?

Yes No

$2 b$. How do you decide if an estimate is OK?

About how much is $27 * 43$ ?

\section{Allie's way:}

$27 \cdot 43$

My estimate is 800 .

I covered up the ones digits and then multiplied the tens digits like this:

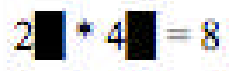

Then I added two zeros because 1 covered up two digits and got 800 .

4a. Use Allie's way to estimate the answer to $21 \star 43$.

4b. Did Allie get the same estimate for these two number problems? 